\title{
Recognition of Powdery Mildew Disease for Betelvine Plants Using Digital Image Processing
}

\author{
Mr.J.Vijayakumar ${ }^{1} \quad$ Dr.S.Arumugam ${ }^{2}$ \\ ${ }^{1}$ Research scholar, Nandha College of Technology- Erode. Tamilnadu, India. \\ vijiece@yahoo.co.in \\ ${ }^{2}$ Chief Executive officer, Nandha Engineering College- Erode. Tamilnadu, India. \\ arumugamdote@yahoo.co.in
}

\begin{abstract}
The fresh leaves of betel vine are generally known as paan in India, which are inspired by about 20 - 30 million people in the country. It is cultivated in India about 75,000 hectares with an annual production worth about Rs. 1000 millions. Betelvine plants may have various disease infected in the entire plantation without any early indications of the diseases. The aim of this paper is to recognize powdery mildew disease in the betelvine plants using digital image processing and pattern recognition techniques. The digital images of the betelvine leaves at various stages of the disease are collected from different plants using a high resolution digital camera and it is stored with JPEG format. The image analyses of the leaves are done using the image processing toolbox in MATLAB which provides the standard patterns of the digital images. Using RGB encoding technique the red, green and blue components of the preprocessed image were separated, which forms the pattern to be compared. These patterns and images of various healthy betelvine leaves at different stages in various days are collected and stored in the system. The mean and median values for all sample leaves are computed and calculated values are stored in the system. The mean and median values of test leaves are computed and compared with the stored values. As the result of this comparison, it is identified whether test leaves are affected by powdery mildew disease or not. Finally this analysis helps to recognize the powdery mildew disease can be identified before it spreads to entire crop.
\end{abstract}

\section{KEYWORDS}

Powdery mildew Disease, Piper betel Linn, and Oidium piperis

\section{INTRODUCTION}

Piper betel Linn. (Family Piperaceae) commonly known as the betelvine in English and Vettrilai in Tamil. Betelvine is an important medical and enjoyable plant in Southeast Asia. The most probable place of origin of betelvine is Malaysia but today the plants are also cultivated in India, Srilanka, Bangladesh, Burma and Nepal. Betelvine leaves are the most important plant part and are of medicinal, religious and traditional value in Southeast Asia. In India it is customary to serve betelvine leaf on various social, cultural and religious occasions and is also offered to guests as a mark of respect. Based on the color, size, taste and aroma there are many varieties of betelvine leaf and some of the most popular Indian varieties are the Magadhi, Venmony, Mysore, Salem, Calcutta, Banarasi, Kauri, Ghanagete and Bagerhati. The betelvine leaf is mainly used to conventional medicines for the treatment of stomach complaints, infections. Some evidence suggests that betelvine leaves have immune boosting properties as well as anticancer properties. Lots of analysis is going on in the field of betelvine diseases for various 
centers in India under the name "ALL INDIA NETWORKING PROJECT IN BETELVINE". During cultivation of betelvine big loss for the farmers are disease affected by betelvine plants. The most important

diseases of betelvine leaf are Powdery mildew, Foot Rot, Leaf Rot and Leaf Spot. It occurs in a very virulent form and if not controlled, causes widespread injure and even total demolition of the entire of betelvine plantations. The farmer is not able to identify the disease at an early stage to initiate preventive action due to the non-availability of modern technology. So for each farmer, to have access to the modern technology there is a need to construct modern commercial farm. This has been the base to develop a new tool to identify the disease well in advance to enhance the cultivation. Digital Image processing is mainly used as a tool for recognition of Powdery mildew disease for the Betelvine plant.

\section{COMPUTERIZED IMAGE ANALYZING SYSTEM}

Essentially when a farmer envisages the Powdery mildew disease for betelvine plant is in the developed stage after which identification cannot save the plant. The Powdery mildew disease spreads to the complete crop and the total plantation gets destructed within few days. Powdery mildew disease emerges on the undersurface of the leaves as white to brown powdery patches. Human eye cannot visualize the Powdery mildew disease at an initial stage. So we are using computerized image analyzing system in which minute change in the form of color in leaves can be detected at an early stage.

\section{POWDERY MILDEW DISEASE}

Powdery mildew is sourced by Oidium piperis. The disease shows on the undersurface of the leaves as white to brown powdery patches. The photograph is shown in figure 1 and figure 2 for front and back view of Powdery mildew infected betelvine leaf.

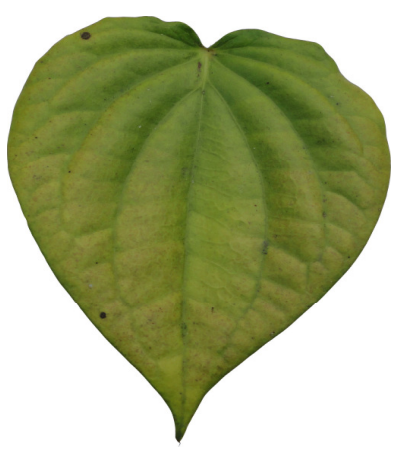

Figure 1. Front view

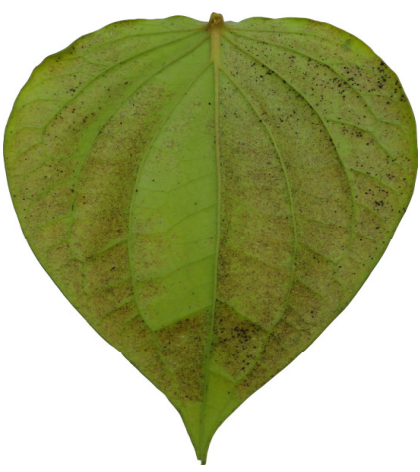

Figure 2. Back view

These infected areas gradually increase in size and repeatedly combine with each other. They vary in size from a few to $40 \mathrm{~mm}$ in diameter and are covered by dusty growth which is fairly thick in cases of sever attack. Areas on the upper surface corresponding to patches on the under 
surface appear yellowish, raised and irregular in outline. Young leaves when attacked fail to grow and become deformed, the surface being cracked and the margin turned inwards. Such leaves present a pale appearance and drop with slight disturbance. The disease is more prevalent in old

plantations. The disease has been reported to be in the leaves only and it has been found to disappear during the hot season.

\section{APPROACH FOR DISEASE IDENTIFICATION}

The betelvine leaves are washed properly to remove the dust particles. Three different categories of betel vine farms were chosen for study. Digital imaging technique is divided in three phases respectively as,

\footnotetext{
$>$ Normal leaves phase

$>$ Fully Infected leaves phase

$>$ Test leaves phase
}

Normal leaves phase consists of without any disease infected in the betelvine leaf. Fully Infected leaves phase consisted of visually identifiable infected leaf, samples are collected for normal leaves and various stages of Powdery mildew disease. Test leaves phase consists of visually unidentifiable infected leaf, samples are collected at various stages of the Powdery mildew disease. Ten samples from each phase were taken for this paper. The size of all the digital images are 256 x 256.To eliminate the background using photo shop 7.0 and background was chosen to be white and these digital images are stored in the system. This stored digital images are given as input to the MATLAB file and the R,G,B color components are seperated and find the mean and median values for all healthy and infected leaves and calculated values are stored in the system. For the test leaf, compute mean and median values and compare all the stored values, to recognize the diseased betelvine leaf affected by powdery mildew disease.

\section{RESULT}

\subsection{FIRST EXPERIMENT}

The First experiment of the paper is all the normal and infected leaves are given as input to the MAT LAB and RGB color components are separated. The mean values are calculated for front and back view of each component and calculated mean values are stored in the system and test leaves are given as input to the MAT LAB and RGB color components are separated and the mean values are calculated for front and back view of each component and calculated mean values are stored in the system. To compare all the stored results and recognize whether Powdery mildew disease infected or not in the test betelvine leaf, the mean values of Red component for normal leaves, infected leaves and test leaves front and back views are shown in 
figure 3 and figure 4 . The mean values of green component for normal leaves, infected leaves and test leaves front and back views are shown in figure 5 and figure 6 . The mean values of Blue component for normal leaves, infected leaves and test leaves front and back views are shown in figure 7 and figure 8 .

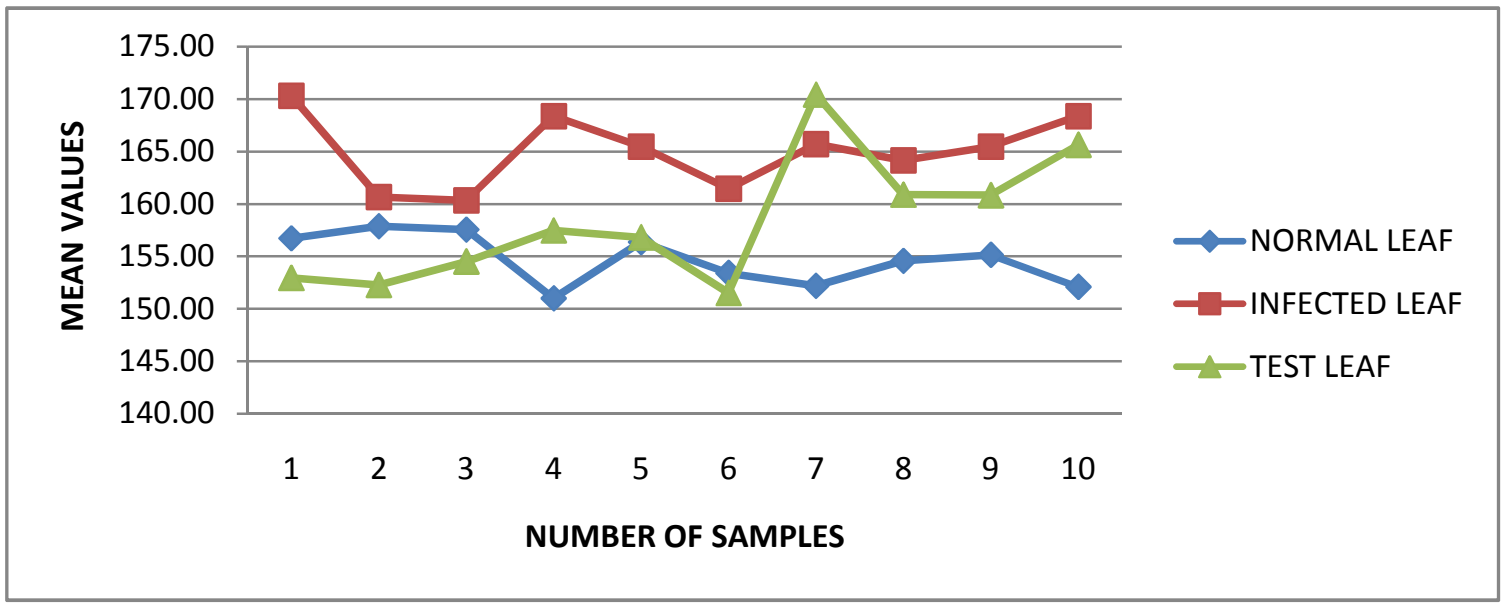

Figure 3. Front view for RED component

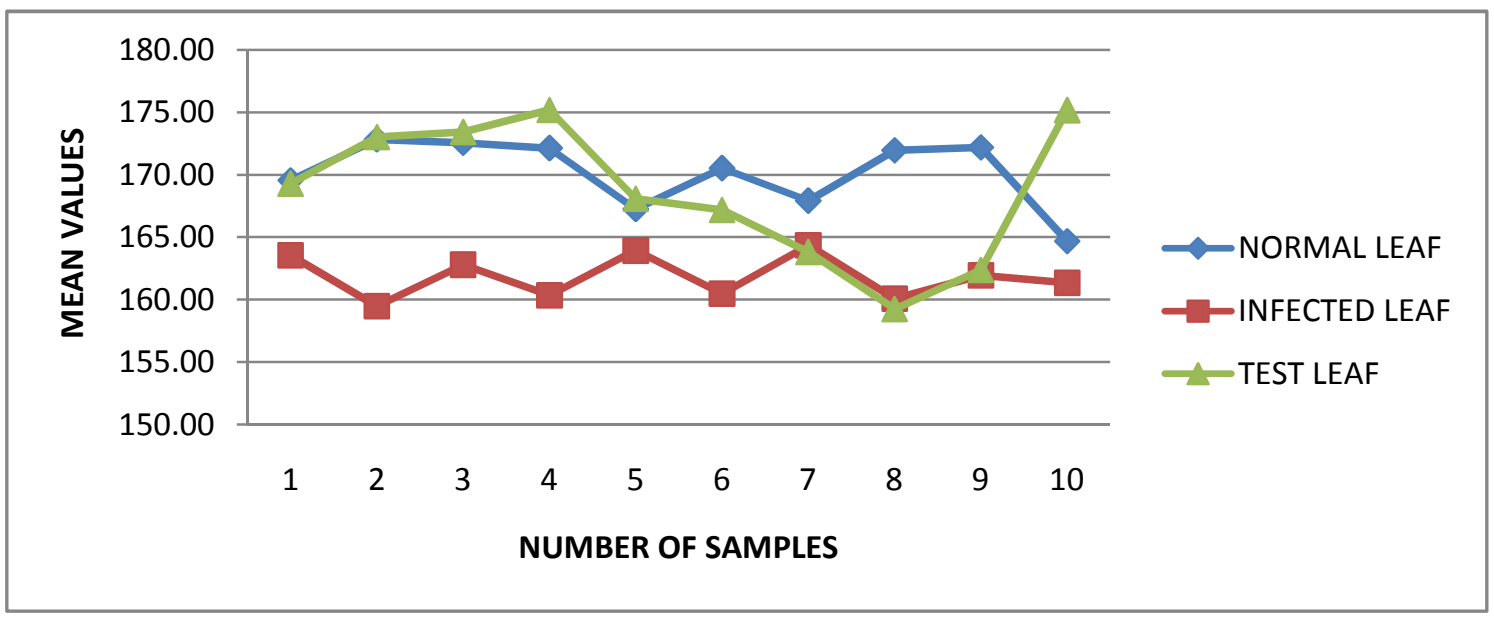

Figure 4.Back view for RED component 
International Journal of Distributed and Parallel Systems (IJDPS) Vol.3, No.2, March 2012

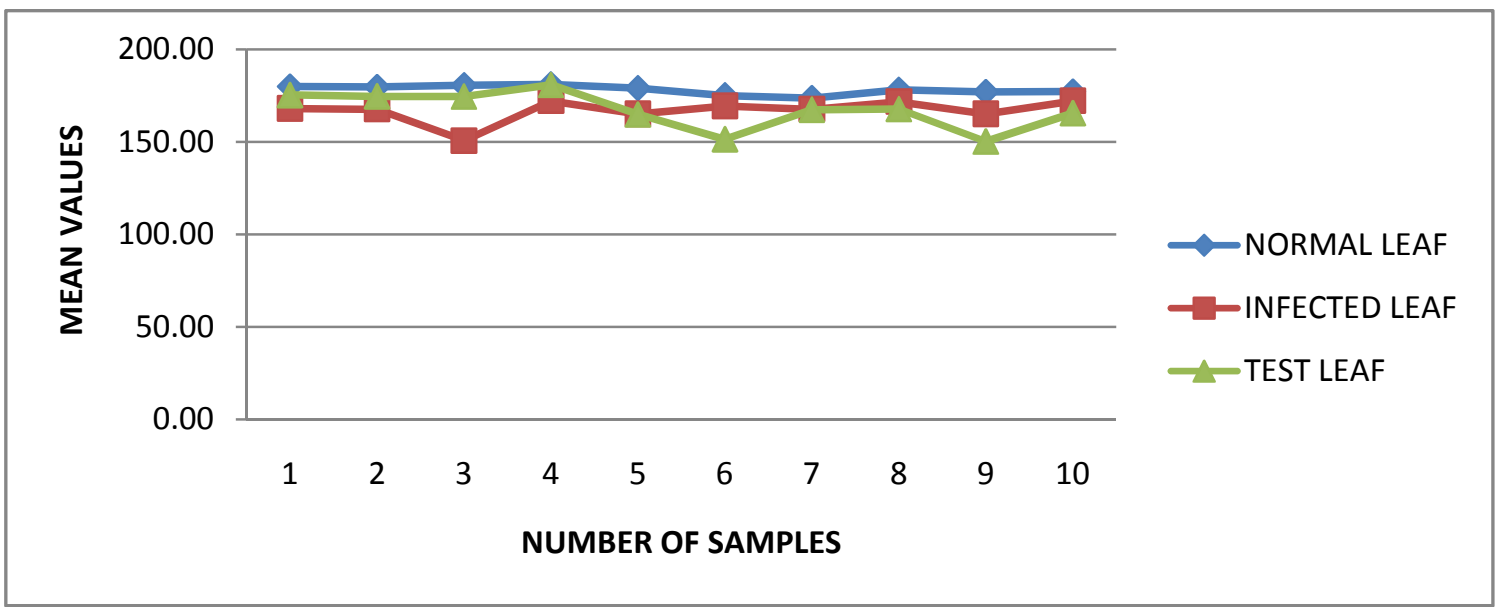

Figure 5. Front view for GREEN component

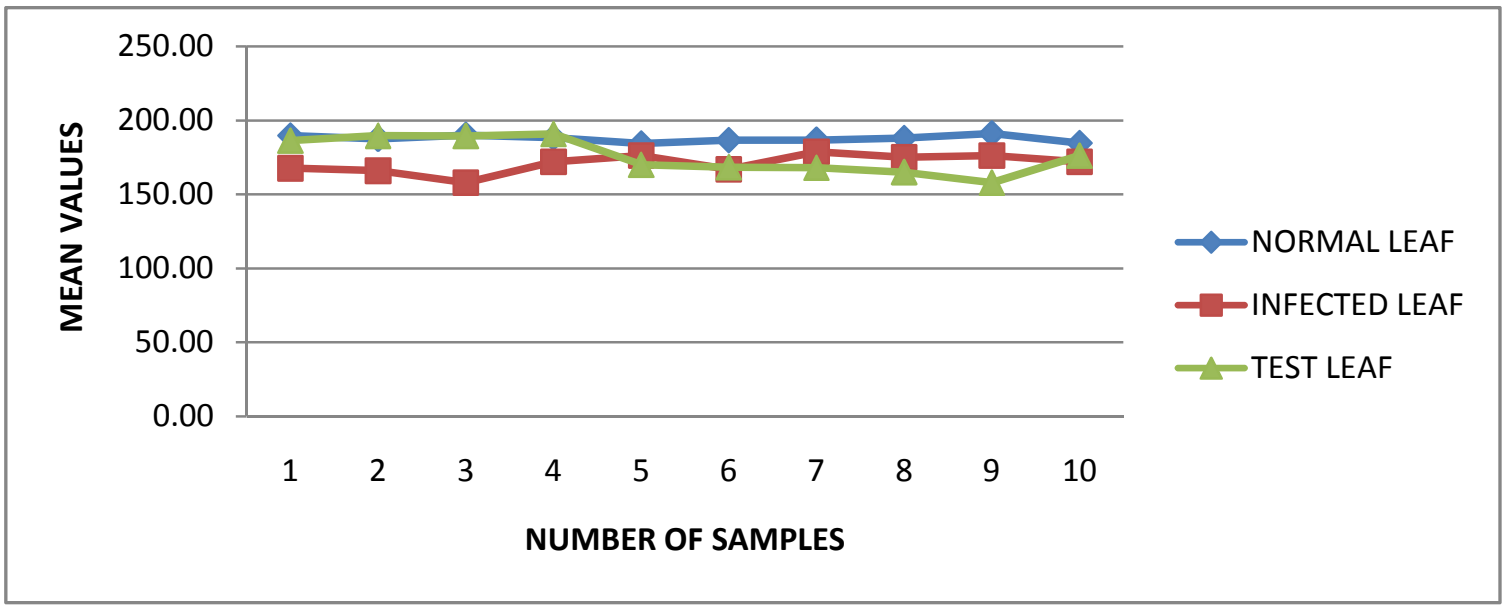

Figure 6. Back view for GREEN component

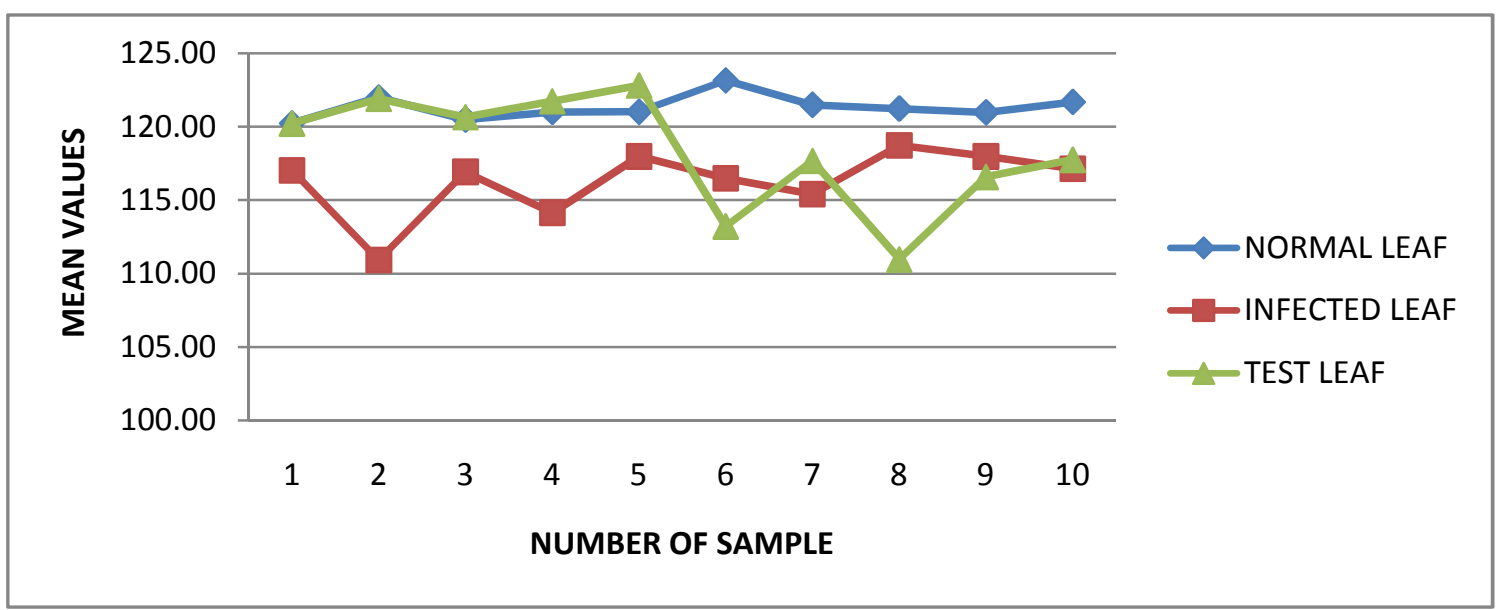

Figure 7. Front view for BLUE component 
International Journal of Distributed and Parallel Systems (IJDPS) Vol.3, No.2, March 2012

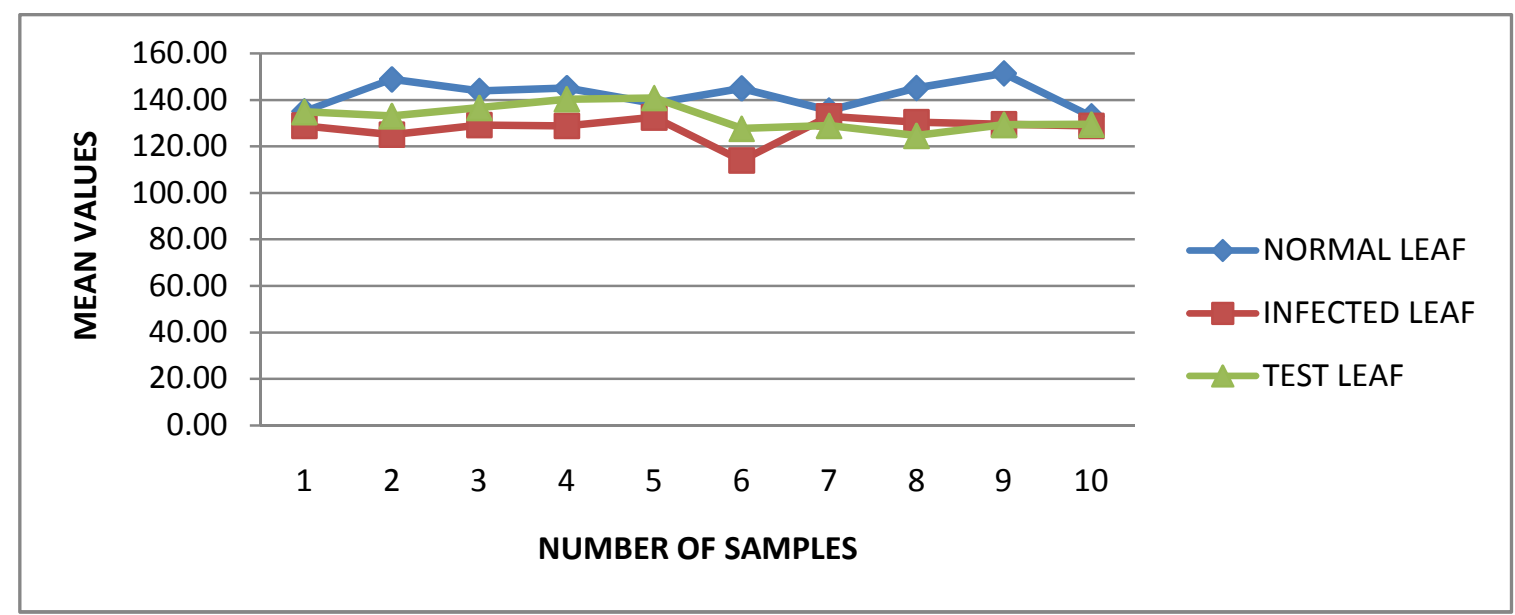

Figure 8. Back view for BLUE component

In normal leaves, front view of Red component mean value ranges from 151 to 157.85 and back view of Red component mean value ranges from 164.67 to 172.82 . In infected leaves, front view of Red component mean value ranges from 160.34 to 170.29 and back view of Red component mean value ranges from 159.46 to 164.34.In test leaves, first six samples of front view Red component mean value ranges from 151 to 157.85 and back view of Red component mean value ranges from 164.67 to172.82 and last four samples of front view Red component mean value ranges from 160.34 to 170.29 and back view of Red component mean value ranges from 159.46 to 164.34 .

In normal leaves, front view of green component mean value ranges from 173.50 to 180.96 and back view of green component mean value ranges from 184.22 to 190.97.In infected leaves, front view of green component mean value ranges from 150.52 to 172.07 and back view of green component mean value ranges from 157.89 to 178.71.In test leaves, first six samples of front view green component mean value ranges from 173.50 to 180.96 and back view of green component mean value ranges from 184.22 to 190.97 and last four samples of front view green component mean value ranges from 150.52 to 172.07 and back view of green component mean value ranges from 157.89 to 178.71 .

In normal leaves, front view of blue component mean value ranges from 120.23 to 123.14 and back view of blue component mean value ranges from 132.94 to 151.33. In infected leaves, front view of blue component mean value ranges from 110.92 to 118.71 and back view of blue component mean value ranges from 113.90 to132.40.In test leaves, first six samples of front view blue component mean value ranges from 120.23 to 123.14 and back view of blue component mean value ranges from 132.94 to151.33 and last four samples of front view blue component mean value ranges from 110.92 to 118.71 and back view of blue component mean value ranges from 113.90 to 132.40 .

To compare all the ten test sample leaves of mean values from stored mean values of normal and infected leaves. The result is first six test sample leaves are uninfected or normal leaves and the remaining test sample leaves are infected leaves. 
International Journal of Distributed and Parallel Systems (IJDPS) Vol.3, No.2, March 2012

\subsection{SECOND EXPERIMENT}

The second experiment of the paper is all the normal and infected leaves are given as input to the MAT LAB and RGB color components are separated. The median values are calculated for front and back view of each component and calculated median values are stored in the system and test leaves are given as input to the MAT LAB and RGB color components are separated and the median values are calculated for front and back view of each component and calculated median values are stored in the system. To compare all the stored results and identify either disease infected or not in the test betelvine leaf. The median values of Red component for normal leaves, infected leaves and test leaves front and back views are shown in figure 9 and figure 10 . The median values of green component for normal leaves, infected leaves and test leaves front and back views are shown in figure 11 and figure 12 . The median values of Blue component for normal leaves, infected leaves and test leaves front and back views are shown in figure 13 and figure 14.

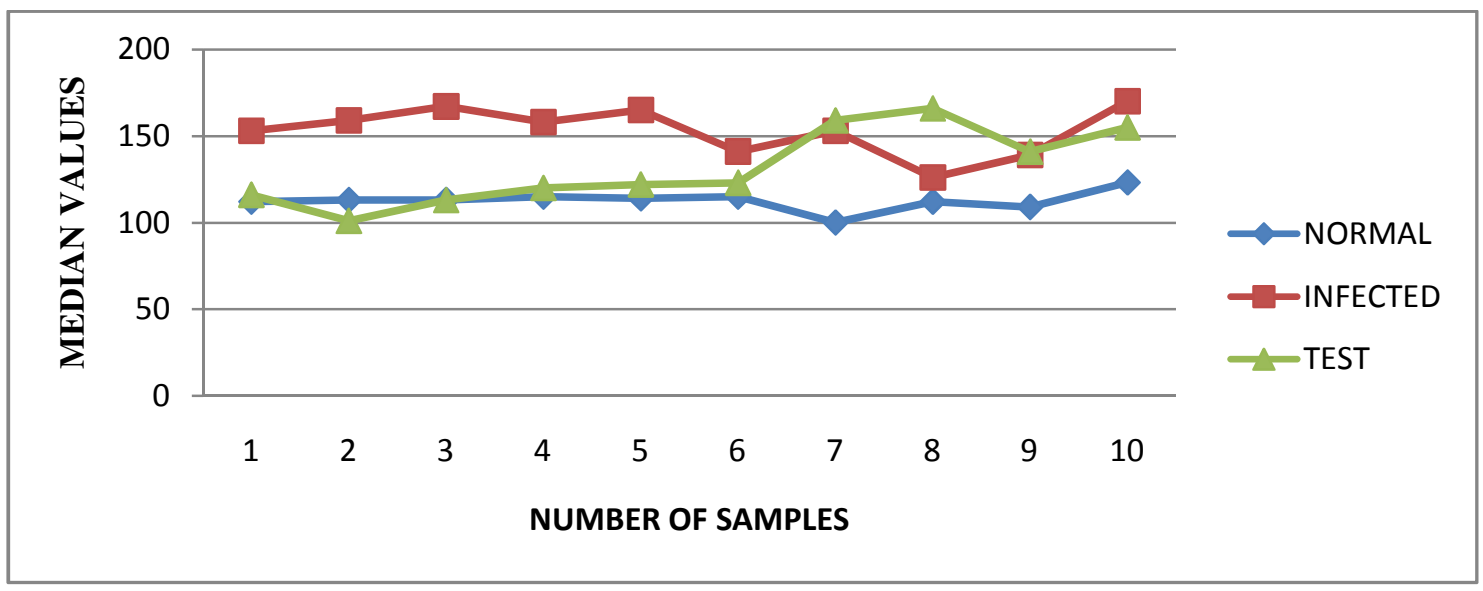

Figure 9. Front view for RED component 
International Journal of Distributed and Parallel Systems (IJDPS) Vol.3, No.2, March 2012

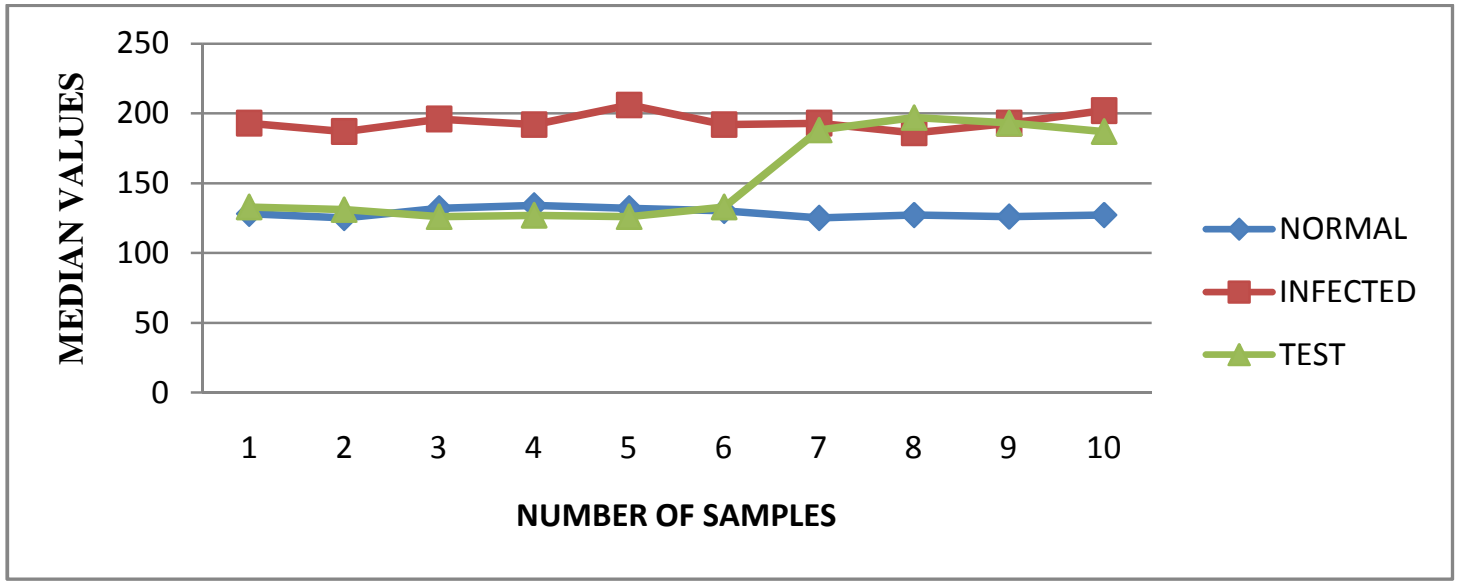

Figure 10.Back view for RED component

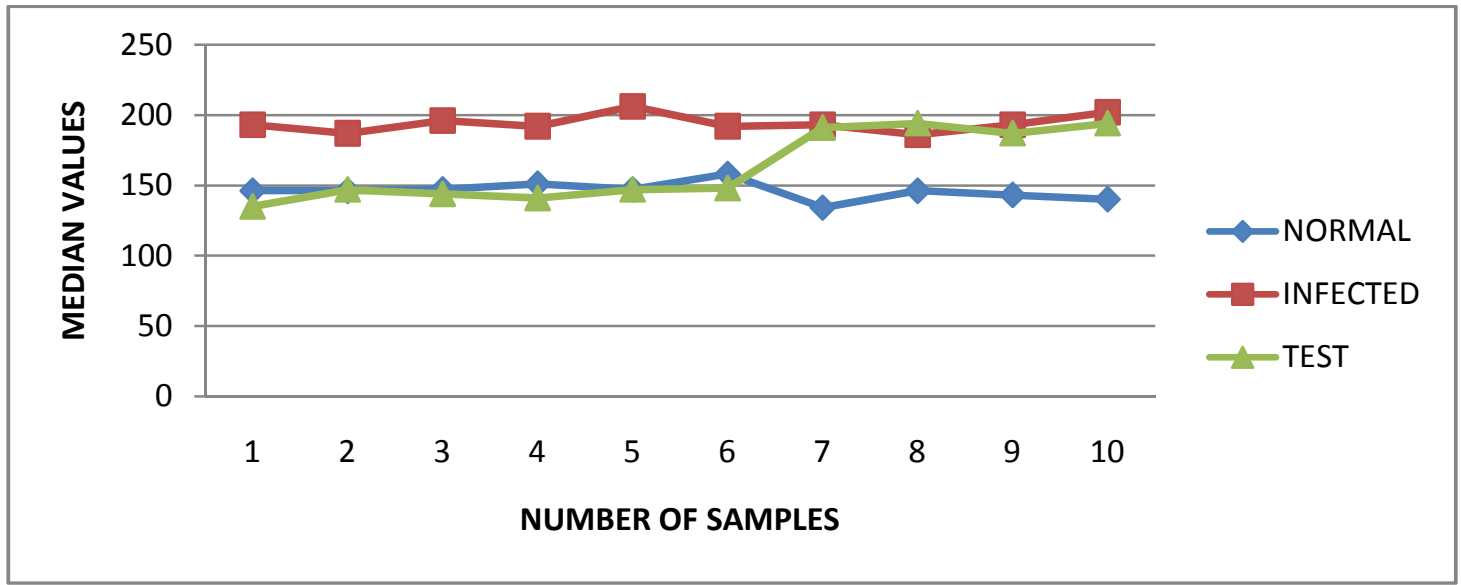

Figure 11. Front view for GREEN component

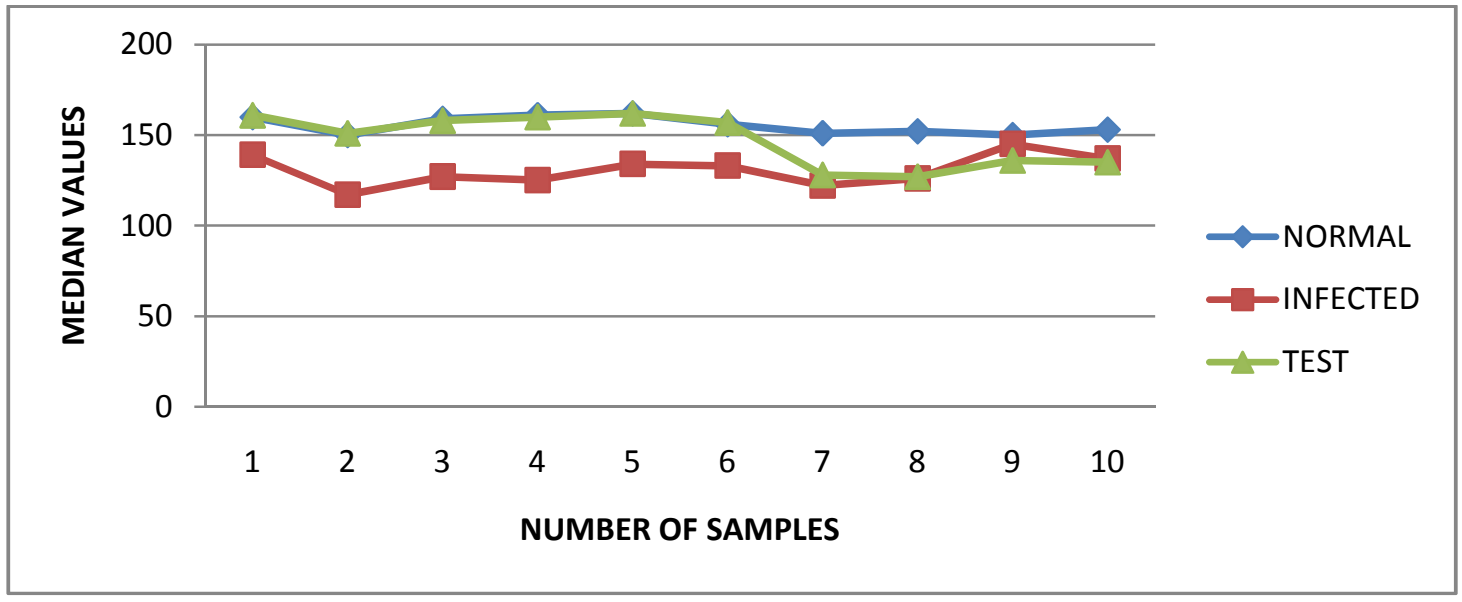


International Journal of Distributed and Parallel Systems (IJDPS) Vol.3, No.2, March 2012

Figure 12. Back view for GREEN component

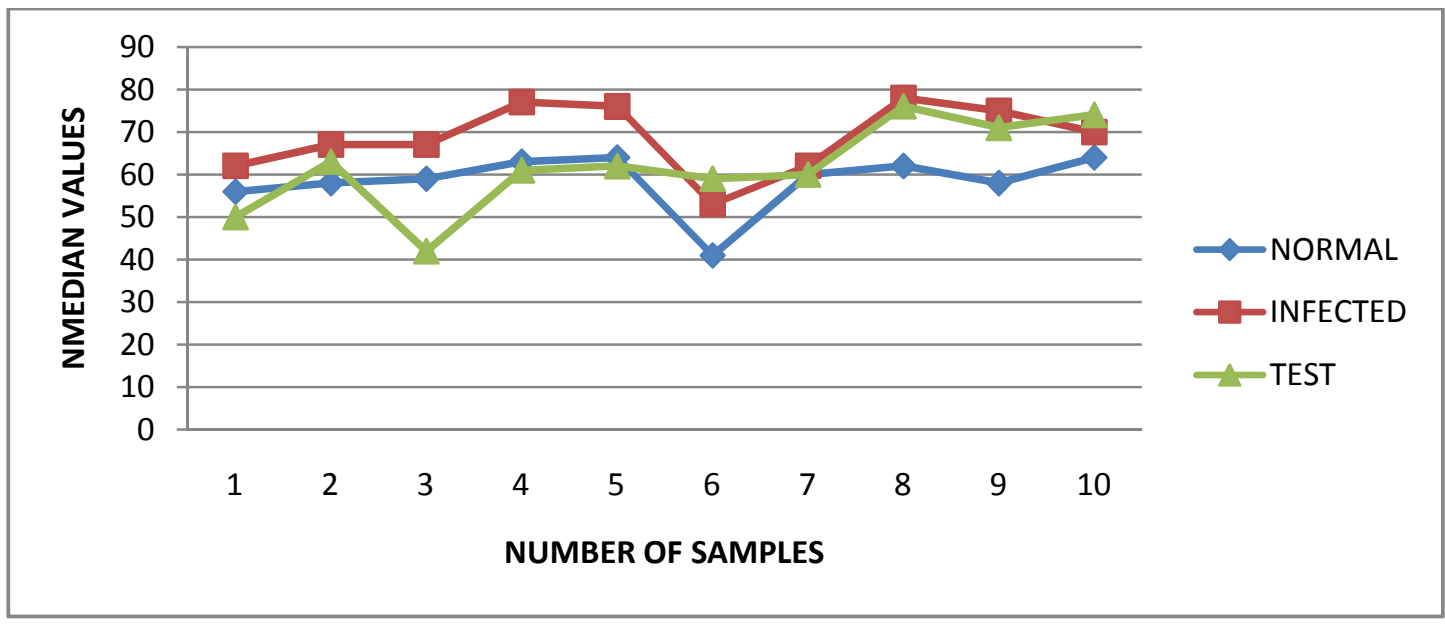

Figure 13. Front view for BLUE component

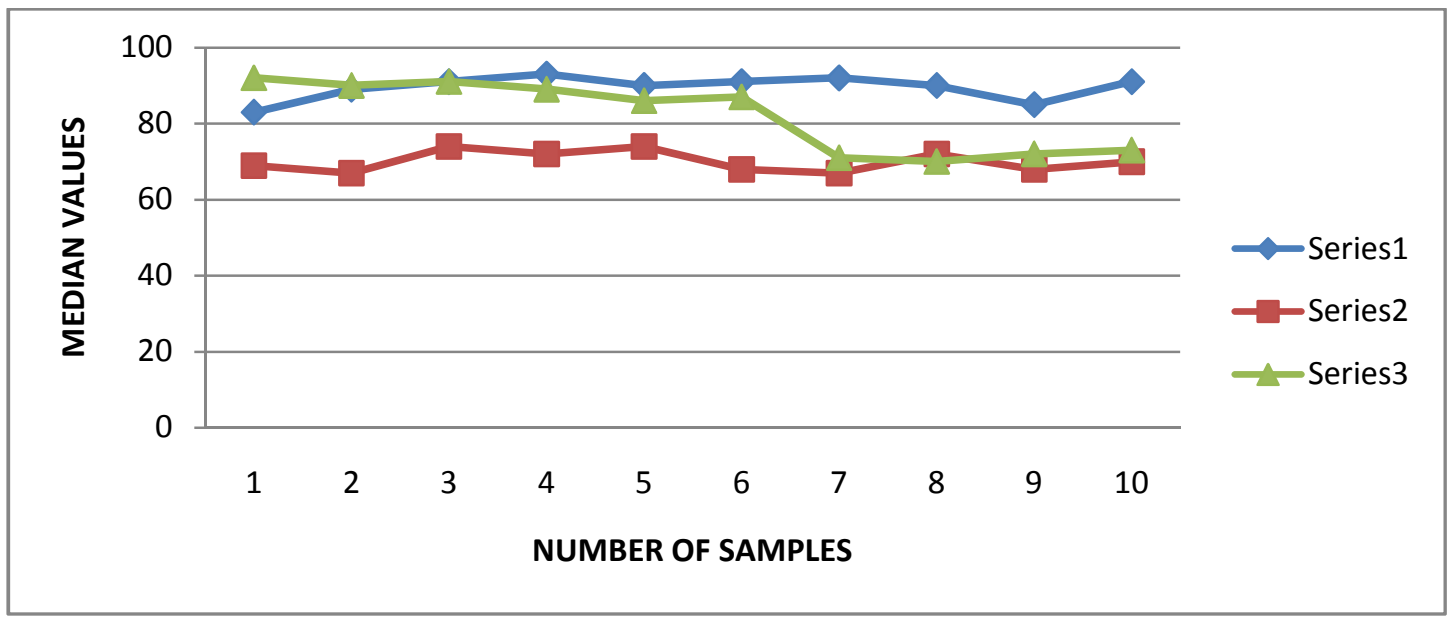

Figure 14. Back view for BLUE component

In normal leaves, front view of Red component median value ranges from 100 to 123 and back view of Red component median value ranges from 125 to 134. In infected leaves, front view of Red component median value ranges from 126 to 170 and back view of Red component median value ranges from 186 to 202.In test leaves, first six samples of front view Red component median value ranges from 100 to 123 and back view of Red component median value ranges from 125 to 134 and last four samples of front view Red component median value ranges from 126 to 170 and back view of Red component median value ranges from 186 to 202.

In normal leaves, front view of green component median value ranges from 140 to158 and back view of green component median value ranges from 150 to 162.In infected leaves, front view of green component median value ranges from 186 to 202 and back view of green component median value ranges from 117 to 145.In test leaves, first six samples of front view green 
component median value ranges from 140 to158 and back view of green component median value ranges from 150 to 162 and last four samples of front view green component median value ranges from 186 to 202 and back view of green component median value ranges from 117 to 145 .

In normal leaves, front view of blue component median value ranges from 41 to 64 and back view of blue component median value ranges from 83 to 93. In infected leaves, front view of blue component median value ranges from 53 to 78 and back view of blue component median value ranges from 67 to 74.In test leaves, first six samples of front view blue component median value ranges from 41 to 64 and back view of blue component median value ranges from 83 to 93and last four samples of front view blue component median value ranges from 53 to 78 and back view of blue component median value ranges from 67 to 74 .

To compare all the ten test sample leaves of median values from stored median values of normal and infected leaves. The result is first six test sample leaves are uninfected or normal leaves and the remaining test sample leaves are infected leaves.

\section{CONCLUSION}

The above proposed methods convey that the betelvine plants disease can be identified disease infected or not in the betelvine leaf and thus preventive action can be taken well in advance such that the entire plantation can be saved before the disease starts to spread. The method of detecting the disease is cost effective and non-destructive as it only requires the digital photograph of the leaf samples in random. The efficiency of the system can be increased by taking the camera parameters, as the camera parameters are considered constant in this project. Periodic inspection of the farm is required to prevent the disease. This method can also be extended to detect all kind of diseases to initiate early preventive action.

\section{REFERENCES}

[1] Sathyabrata Maiti and K.S. Shivashankara ”Betelvine Research Highlights”. (1998).

[2] Dastur.J.F. "Diseases of pan (piper betle) in the general provinces".(1935).

[3] B. Dasgupta, B.Mohanty, P. K. Dutta and Satyabrata Maiti "Phytophthora Diseases of Betelvine (piper betle 1.)" SAARC Jn. of Agri.,(2008), pp (1-19).

[4] Nikhil Kumar "Betelvine (piper betle 1.) Cultivation: A Unique Case Of Planstablishment Under Anthroprgenically Regulated Microclimatic Conditions" Indian Journal of History Of Science (1999), pp(19-32).

[5] Bibekananda Mohanty, Partha Datta, B. Dasgupta and Dalim Kumar Sengupta ntegrated Management Of Foot And Leaf Rot Of Betelvine" SAARC Jn. of Agri.,(2011), pp (83-91). 
International Journal of Distributed and Parallel Systems (IJDPS) Vol.3, No.2, March 2012

[6] Shete M. H., Dake G. N., Gaikwad A. P. and Pawar N. B. "Chemical Management of Powdery Mildew of Mustard" Journal of Plant Disease Sciences, Volume:3, Issue: 1 (2008),pp(46-48).

[7] P.Guha "Betel Leaf: The Neglected Green Gold of India" Journal of Human Ecology (2006), pp (87-93).

[8] J.Vijayakumar and Dr.S.Arumugam "Study of Betelvine Plants Diseases and Methods of Disease Identification using Digital Image Processing" European Journal of Scientific Research Vol.70 No.2 (2012), pp(240-244).

[9] J.Vijayakumar and Dr.S.Arumugam "Foot Rot Disease Identification for the Betelvine Plants using Digital Image Processing" Journal of Computing,Volume 3, Issue 2,February 2011,pp ( 180-183).

\section{AUTHOR'S BIOGRAPHY}

Mr. J. Vijayakumar received the Bachelor of Engineering in Electronics and Communication Engineering from Maharaja Engineering College, affiliated to Bharathiar university-Coimbatore, in the year of 2003 and Master of Engineering in Applied Electronics from Bannari Amman Institute of Technology, affiliated to Anna university-Chennai, in the year of 2005 . He undertook his Ph.D. work in Anna University of Technology- Coimbatore under the guidance of Dr. S. Arumugam. He is Assistant Professor of Electronics and Communication Engineering in Nandha College of Technology- Erode. His area of significance is Digital Image Processing.

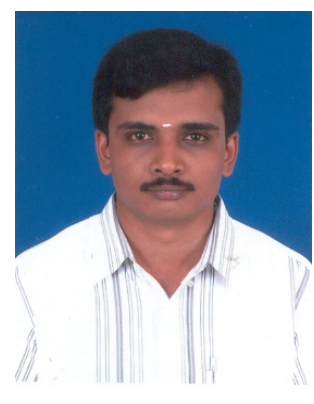

Dr. S. Arumugam completed bachelor of Electrical and Electronics Engineering and M.Sc(Engg)., in Applied Electronics from PSG College of Technology affiliated to University of Madras. He obtained Ph.D., in Computer Science and Engineering from Anna University. He is a member in The Directorate of Technical Education since 1974 onwards. He had retired from Government service as additional Director of Technical Education and Chairman for Board of Examinations. He served as Chief member of various boards of studies. He is a fellow member in IE, IETE, senior member in CSI and member in IEEE. He has guided 15 Ph.D

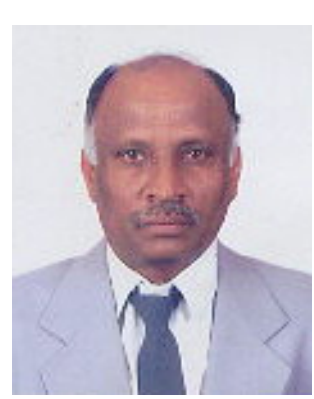
scholars and $23 \mathrm{Ph} . \mathrm{D}$ scholars are presently working under his guidance. He has so far published over 100 papers in various National and International Journals and Conferences. His area of interest is Digital Image Processing. Now he is working as Chief Executive officer, Nandha Educational Institution- Erode. 